\title{
CORPO E SUBJETIVIDADE NA TRANSEXUALIDADE: UMA VISÃO ALÉM DA (DES)PATOLOGIZAÇÃO
}

\section{CUERPO Y SUBJETIVIDAD EN TRANSEXUALIDAD: UNA VISIÓN ADEMÁS DEL (DES)PATOLOGIZAÇÃO}

\author{
${ }^{1}$ Leonardo Canez Leite \\ ${ }^{2}$ Taiane da Cruz Rolim
}

\section{RESUMO}

Este trabalho tem como objetivo, a partir de uma metodologia de revisão bibliográfica, particularmente dos estudos culturais, discutir a transexualidade no contexto das políticas de saúde pública no Brasil, frente à luta pelo reconhecimento de transexuais. Nesse sentido, busca-se problematizar as diferentes classificações e intervenções que foram decisivas na estruturação da transexualidade enquanto transtorno de identidade de gênero, atenuando as possibilidades de ditos da transexualidade a uma patologia. Contudo, relatase que a experiência trans é povoada por corpos que escapam, que não conseguem encontrar sentido existencial nas cartografias disponibilizadas e aceitas socialmente. Baseando-se em compreensões concebidas a partir da instauração do dispositivo da sexualidade, propõem-se à desconstrução de corpos a partir da lógica binária de gênero. Portanto, toda construção política dos corpos desvela e articula sexualidade, gênero e direitos humanos com ênfase na construção de uma democracia pós-identitária.

Palavras-chave: Transexualidade, Despatologização, Cirurgia de transgenitalização

\begin{abstract}
Este trabajo tiene como objetivo, empezar de una metodología de revisión bibliográfica, particularmente del estudios culturales, discutir la transexualidad en contexto de la política de salud pública en Brasil, frente la lucha pelo reconocimiento de transexuais. En esse sentido, se busca problematizar las diferentes clasificación y intervención que se fue decisiva en la estructuración de la transexualidad mientras trastorno de identidad de género, atenuando las posibilidades del dichos de la transexualidad la una patología. No
\end{abstract}

\footnotetext{
${ }^{1}$ Mestrado em Direito e Justiça Social da Faculdade de Direito da Universidade Federal do Rio Grande, UFRG. Rio Grande, RS, Brasil. E-mail: indexlaw.ojs@hotmail.com

${ }^{2}$ Mestranda em Direito e Justiça Social pela Universidade Federal do Rio Grande/FURG. Rio Grande. - RS, Brasil.

E-mail: indexlaw.ojs@hotmail.com
} 
obstante, se relata que la experiencia trans está poblada por cuerpos que escapan, que no pueden tener sentido existencial en la cartografía disponible y socialmente aceptable. Basar-se en entendimientos diseñadas desde el establecimiento del dispositivo de la sexualidad, proponer a la deconstrucción de los cuerpos de la lógica binaria de género. Por lo tanto, toda la construcción política del cuerpos desvela y articula la sexualidad, género y derecho humanos con énfasis en la construcción de una democracia posterior a la identidad.

Keywords: Transexualidad, Despatologización, Cirugía de reasignación

\section{INTRODUÇÃO}

O presente trabalho tem como objetivo, refletir de forma a propiciar uma contribuição teórica e reflexiva, sobre a análise de uma temática de grande relevância atual no contexto social sobre a transexualidade. Buscando-se mecanismos que sejam capazes de desconstruir o carácter patologizante denotada até mesmo no sufixo empregado na palavra "transexualísmo". Não obstante,

é um tema que tem sido recorrente em pesquisas e está sendo objeto de estudos internacionais e nacionais, quer sobre a ótica médica, bioética ou, inclusive, sobre o olhar das identidades de gênero, embora no Brasil ainda vigore uma interpretação como anteriormente mencionada, patologizada.

Em primeiro lugar, relata-se um aparato histórico sobre a transexualidade com o objetivo de contextualizar a problemática e percorrer atos de disposições do próprio corpo através de cirurgia de transgenitalização. Busca-se à saúde desta população, envolvendo prestações de serviços públicos, sob a ótica de uma concretização baseada no direito fundamental à saúde. Dessa forma, o recorte principal do trabalho concentra-se no direito à saúde dos transexuais e no fato de que a inequívoca consolidação desse direito compreende, dentre outros aspectos, também a saúde mental, à cirurgia de redesignação sexual garantidos pelo Sistema Único de Saúde (SUS).

É evidente o recrudescimento dos sofrimentos psíquicos e os desconfortos gerados a partir das discordâncias entre o sexo biológico e a identidade de gênero. Obviamente, não são os únicos problemas enfrentados por estas pessoas. Isto porque ainda percorrem um longo caminho legal de proteção do nome e suas possibilidades legais como forma de efetividade do direito de personalidade. Ademais é notável que o sistema jurídico ainda 
carece de leis específicas para o tratamento dessas questões. Sendo assim, serão analisados também alguns projetos de lei, assim como o princípio da dignidade da pessoa humana.

A partir dessas questões a pesquisa partiu com sua gênese na revisão crítica do referencial teórico em bioética e saúde, levando em consideração uma leitura interpretativa de autores impor-tantes que abordam essas questões, assim como também sobre a transexualidade e seus dilemas éti-cos e humanos. As propostas teóricas foram então delineadas de uma construção sintética dos con-ceitos que envolvem os termos identidade de gênero e transexualidade, além de uma análise sobre a dignidade humana e a cirurgia de redesignação sexual com os devidos aspectos referentes à legisla-ção pátria.

Assevera-se que o tema está diretamente relacionado aos direitos à identidade sexual e à saúde. As normas brasileiras são omissas na matéria, ocasionando uma série de discussões em nível doutrinário e jurisprudencial que buscam a concretização desses direitos. A transexualidade, atualmente é um dos fenômenos que mais tem crescido tanto na medicina quanto na bioética e até mesmo a respeito das identidades de gênero, mesmo que ainda necessite de regulamentação jurídica adequada. É mais do que essencial o reconhecimento do direito à saúde do transexual, o seu direito de dispor do próprio corpo e que a sua dignidade humana plena, completa, enfim, seja compreendida e respeitada. Assim garantindo a cidadania no segmento social através de políticas públicas que assegurem os avanços nas questões de gênero e sexualidade.

\section{BREVE CRONOGRAMA HISTÓRICO: UMA CONSTRUÇÃO DA TRANSEXUALIDADE}

De antemão, cabe destacar o alcance histórico da transexualidade, comecemos por 1949, onde David Cauldwell que era um sexólogo utilizou pela primeira vez, o termo "transexualismo" na origem de um artigo publicado em uma revista de educação sexual, cujo título "Transexualis Psychopathia), era para fazer referência a um pedido de "transmutação" de mulher para homem (SCHILT, 2008).

Em 1952, George Jorgensen um ex-soldado americano, após suceder a uma série de tratamentos hormonais, visando à feminilidade, se sujeitou a cirurgia de transgenitalização na Dinamarca, retirando seu órgão biológico e assumindo o nome de Christine Jorgensen, o seu caso ganhou grande repercussão mundial e, foi relatado como uma bomba que estourou na mídia, contendo em capa de jornal, uma notícia cujo título relata: "Ex-Gi Becomes 
Blonde Beauty" (Antigo-George Se Torna Beleza Loira). Jornal New York Daily New de $1^{\circ}$ de dezembro de 1952.

Em 1953, Harry Benjamin, um endocrinologista, em sua concepção biológica, partiu da ideia de que o "sexo" é constituído de múltiplos sexos: o cromossomático ou genético, o gonádico, o fenotípico, o psicológico e o jurídico, entendendo que o sexo cromossomático ou genético seria o encarregado pela definição do sexo e do gênero:

[...] o transexual se sente uma mulher ("aprisionada em um corpo de homem") e se sente atraído por outros homens. Isso faz dele um homossexual se seu sexo for diagnosticado de acordo com seu corpo. No entanto, ele se autodiagnostica segundo seu sexo psicológico feminino. Ele sente atração por um homem como heterossexual, ou seja, normal. (Benjamin, 2001, p.30 citado por Bento, 2006, p. 151).

Referindo-se ao caso de divergência psico-mental do transexual, Benjamin isola o fenômeno do "transexualismo" e o batiza como tal em 1960, definindo um diagnóstico do que seria o "verdadeiro transexual". No entanto, foi durante os anos de 1960 e 1970 que os clínicos instauraram a aplicação deste termo, para designar pessoas que viveriam em condições melhores, após o processo de culminação da cirurgia de transgenitalização.

Em 1966, Harry Benjamin publicou o livro “The Transsexual Phenomenon”, onde forneceu bases para diagnosticar o "verdadeiro" transexual. Neste livro, foram estabelecidos os parâmetros para avaliar se as pessoas, que chegam as clínicas ou aos hospitais solicitando a cirurgia de transgenitalização são "transexuais de verdade” (BENTO, 2006). Uma vez que:

\footnotetext{
Para Benjamin, a cirurgia seria a única terapia possível para os/as "transexuais verdadeiros". Ao localizar a origem das identidades de gênero no sexo cromossomático e a sexualidade no sexo germinal, Benjamin reafirma e reatualiza Tardieu, para quem a verdade última dos sujeitos deveria ser buscada não nos comportamentos, mas na biologia dos corpos - no caso de Benjamin, principalmente nos hormônios. A consequência imediata das posições de Benjamin é a definição da transexualidade como uma enfermidade. (BENTO, 2006, p.149150)
}

Benjamin propôs uma tabela na qual classificou níveis de indecisão e desorientação sexual e de gênero. Em um conjunto de seis tipos (pseudo-travesti masculino; travesti fetichista masculino; travesti verdadeiro masculino, mas sem convicção; transexual não cirúrgico incerto entre travesti e transexual, pode rejeitar seu gênero; transexual de intensidade moderada, feminino preso em um corpo masculino; transexual de alta intensidade, feminino inversão "psicossexual”). 
No Brasil, a primeira cirurgia de transgenitalização ocorreu em 1971, quando o transexual Waldir Nogueira, foi operado pelo cirurgião Roberto Farina. A cirurgia foi um sucesso, porém o médico foi processado criminalmente e, também, pelo Conselho Federal de Medicina. No qual foi considerado culpado nos dois processos, e condenado à perda do direito ao exercício da medicina.

Em 1977, sexologistas ligados a questões de gênero criaram a "Harry Benjamin International Gender Dysphoria Association” - (HBIGDA) - Associação Internacional de Disforia de Gênero Harry Benjamin, empregando no nome a expressão "disforia de gênero" cunhada por John Money, com Norman Fisk e o cirurgião plástico Donald Laub. A HBIGDA legitimou-se, mundialmente, como a encarregada pelo preceito do "tratamento" para as pessoas transexuais.

Em 1987, foi incluído no "Diagnostic and Statistical Manual of Mental Disorders" (DSM-

III) - Manual Diagnóstico e Estatístico das Desordens Mentais), o "transexualismo" para as pessoas com disforia de gênero que apresentassem, pelo menos dois anos, uma relevância incessante em mudar o sexo biológico do corpo e a circunstância do gênero social. Em 1994, o DSM-IV substituiu o termo "transexualismo" por desordem da identidade de gênero, que é também encontrada na CID-10 (Classificação Internacional de Doenças) e em 2001, o DSM substituiu desordem da identidade de gênero por transtorno de identidade de gênero". (GARCÍA, 2009).

Em 1995, ocorreu no Brasil o primeiro debate sobre o transexualismo com o objetivo de abrir a possibilidade de cirurgia de transgenitalização. No entanto somente em 1997, o Conselho Federal de Medicina através da Resolução $\mathrm{n}^{\circ}$ 1.482, autorizou no Brasil a realização de cirurgias de transgenitalização à título experimental, realizada como designação de pesquisa em hospital universitário ou público.

Em 2006, a Organização Mundial da Saúde inclui o "transexualismo" no CID Classificação Internacional de Doenças (CID-10), no capítulo dos chamados transtornos de identidade sexual, com a seguinte definição:

(F-64.0) Transexualismo Um desejo de viver e de ser aceito como pessoa do sexo oposto, usualmente acompanhado por uma sensação de desconforto ou impropriedade de seu próprio sexo anatômico e um desejo de se submeter a um tratamento hormonal e cirúrgico para tornar seu corpo tão congruente quanto possível com o sexo desejado. 
Em 2008, o Ministério da Saúde regulamentou os procedimentos para a realização da cirurgia pelo Sistema Único de Saúde, por meio da portaria nº 457/2008. Os requisitos para a realização da cirurgia de transgenitalização estão previstos no art. $4^{\circ}$ da resolução 1.955/2010 do Conselho Federal de Medicina:

Art. $4^{\circ}$ Que a seleção dos pacientes para cirurgia de transgenitalismo obedecerá a avaliação de equipe multidisciplinar constituída por médico psiquiatra, cirurgião, endocrinologista, psicólogo e assistente social, obedecendo aos critérios a seguir definidos, após, no mínimo, dois anos de acompanhamento conjunto:

- Maior de 21 anos

- Ausência de características físicas inapropriadas para a cirurgia

- Diagnóstico médico de transgenitalismo

Em 2010 na França, o "transexualismo" deixou de ser considerado transtorno mental, sendo o primeiro país do mundo a tomar esta decisão. Já a Argentina em 2012, aprovou uma lei de identidade de gênero, que prevê a possibilidade de solicitação de correção do sexo e nome nos registros públicos. Conclui-se com a Portaria $n^{\circ} 2.803$ de 2013, onde prevê a realização do procedimento de transformação do fenótipo feminino para masculino. Além da inclusão das mulheres, a nova regra amplia o leque de procedimentos de mudança de sexo para os homens, no âmbito do SUS.

\subsection{ESPÉCIES DE TRANSGENERIDADES}

Transgeneridade é um termo guarda chuva para várias identidades e expressões de gênero (COACCI, 2013). No entanto, visa-se como objetivo a conotação do indivíduo transexual, mas para isso, precisamos identificar os demais termos que poderão assemelharse à transexualidade. Segue abaixo algumas distinções de expressões passíveis de serem confundidas. O indivíduo transexual não se assemelha ao homossexual ou ao travesti (BENTO, 2006), apesar de, o travesti também vivenciar prazer em se vestir com o feitio do seu sexo oposto, apenas o indivíduo transexual tem a impulsão de rejeição ao seu sexo biológico.

Homossexualidade: Refere-se à situação na qual o interesse e o desejo sexual dirigem-se a pessoas do mesmo sexo. É uma das possibilidades de manifestação da sexualidade e afetividade humana (SGRECCIA, 2002). Sendo assim, a homossexualidade não é compreendida como um transtorno médico ou psiquiátrico, nem mesmo há o desejo de mudar de sexo, mas simplesmente ter relações sexuais com indivíduos do mesmo sexo (BENTO, 2006). 
Travesti: Subentende-se que seria o indivíduo que, não se reconhece com o gênero biológico (BUTLER, 2013), mas não há o desejo profundo de mudança de sexo, mas sim, a simples necessidade psíquica de usar roupas do outro sexo (SGRECCIA, 2002). É uma pessoa do sexo masculino que se veste como mulher, se comporta como mulher e se sente mulher, ou vice-versa, uma pessoa do sexo feminino que se veste com roupas masculinas, se comporta e age como se fosse um homem.

Drags: Poderão ser: "drag queens" homens que se vestem de mulher ou "drag king" mulheres que se vestem de homens (SZANIAWSKI, 1999). Os Drags são muito exacerbados na maneira de realçar a figura que buscam parecer ou ser.

Transexual: Se relaciona as pessoas que possuem identidade de gênero oposta ao sexo designado, poderá manifestar o desejo de fazer uma cirurgia no seu corpo para mudar de sexo (VIEIRA, 2008), o que não acontece com as travestis. Muitas travestis modificam seus corpos com ajuda de hormônios, terapias, implantes de silicone e cirurgias plásticas, mas ainda desejam manter o órgão sexual de origem. (CONFERÊNCIA NACIONAL LGBT, 2008).

O que diferencia os "transexuais" dos "drag kings" é que estes não reivindicam "uma" identidade de gênero, mas a legitimidade dos trânsitos, inclusive corporais, entre os gêneros (VIEIRA, 2008). Os hormônios, as cirurgias parciais ou totais das genitálias, o silicone, a maquiagem são utilizados pelos drag kings para construir intencionalmente paródias de gênero, para embaralhar fronteiras. (BENTO, 2006).

Transgênero: Se relaciona às condições cujas características não se mantem no papel social atribuído ao gênero designado no nascimento, entendendo como uma série de expectativas baseadas nas características físicas da genitália biológica (BENTO, 2006). São pessoas que ultrapassam o feminino e o masculino (BUTLER, 2013).

Intersexuais: Definisse como pessoas "portadoras de estado intersexual", as quais apresentam caracteres físicos e funcionais de ambos os sexos (SZANIAWSKI, 1999). O autor afirma que intersexualidade e transexualismo não se confundem, haja vista que o transexual possui perfeita genitália externa e interna de um único sexo, respondendo, porém, psicologicamente aos estímulos do outro. Dessa forma, a defasagem entre o corpo e a psique classifica o indivíduo como transexual.

Hermafroditismo: Refere-se ao termo "hermafrodita" quando aplicado ao indivíduo que possui órgãos reprodutivos dos dois sexos, sendo que, em casos raros, as duas partes do 
aparelho sexual estão bem desenvolvidas, mas geralmente ambas são atrofiadas (SZANIAWSKI, 1999).

Crossdresser: São indivíduos que são de um sexo, mas se vestem como o do outro (BENTO, 2006). Difere dos outros pelo desejo de não assumir publicamente uma identidade emocional, são momentâneos. Não usam hormônios, nem cirurgias corretivas e mantém uma vida condizente com seu sexo biológico (VIEIRA, 2008).

Como veremos, a vida de muitas pessoas são afetadas cotidianamente, por assuntos relacionados com a identidade de gênero o que difere da orientação sexual (COACCI, 2013). Apesar de existirem várias análises da ciência, bioética e interpretações da sociedade, ainda trata-se de um tema em constante desenvolvimento.

\subsection{IDENTIDADES DE GÊNERO VERSUS ORIENTAÇÃO SEXUAL}

O termo "orientação sexual" refere-se como nós nos sentimos em relação à afetividade e sexualidade (LOURO, 2014). No entanto, pronuncia-se orientação e não opção, pois não é algo linear passível de mudança (FOUCAULT, 1997). Contudo, a identidade de gênero, por sua vez, dispõe de pouca compreensão, ao passo que a orientação sexual se caracteriza a quem nos relacionamos e como somos reconhecidos dentro dos padrões de gênero estabelecidos socialmente.

A percepção de humanidade interposta pelo poder social, fere o direito à identidade $\mathrm{e}$ ao reconhecimento da diversidade, apartando o poder de escolha nas ações dos indivíduos (BENTO, 2006). Entretanto, a autora relata que devemos associar a transexualidade como um conflito identitário e não como uma enfermidade, visto que:

\footnotetext{
Nessas experiências, há um deslocamento entre corpo e sexualidade, entre corpo e subjetividade, entre corpo e as performance de gênero. Ainda que o referente da binariedade esteja presente como uma matriz de construção de sentidos, negociados para os sujeitos que transitam entre o masculino e o feminino, essas experiências negam, ao mesmo tempo, que os significados que atribuem aos níveis constitutivos de suas identidades sejam determinados pelas diferenças sexuais. (BENTO, 2006, p.77)
}

A diferença sexual pode levar a uma coisificação do gênero e a um marco implicitamente heterossexual para a descrição dos gêneros, da identidade de gênero e da sexualidade (BUTLER, 2013). Em que pese, o transexual poderá ser heterossexual, 
homossexual ou bissexual - isso não abala o sentimento de não pertencimento ao gênero em que seu sexo o posiciona (BENTO, 2006).

\begin{abstract}
As histórias de mulheres transexuais lésbicas e de homens transexuais gays indicam à necessidade de interpretar a identidade de gênero, a sexualidade, a subjetividade e o corpo como modalidades relativamente independentes no processo de construção das identidades. (BENTO, 2006, p.25).
\end{abstract}

Esse sistema, fundamentado na diferença sexual, nos faz acreditar que deve haver uma concordância entre gênero, sexualidade e corpo. Nesse sentido, Butler ressalta a importância de um espaço para a inclusão de experiências de gênero que estão além de um referencial biológico, sendo importante considerar que as identidades são sempre construídas; elas não são dadas ou acabadas num determinado momento, tanto na dinâmica do gênero como na dinâmica da sexualidade. Deste modo, não se pode estabelecer um momento em que a identidade sexual ou a identidade de gênero seja "assentada" ou "estabelecida", visto que as identidades estão sempre se constituindo, elas são instáveis, fruto da representação humana através da performatividade (BUTLER, 2013) a representação e, portanto, passíveis de transformação.

\title{
3. TRANSEXUALIDADE
}

Primeiramente, cabe ressaltar aqui, a aplicação do termo transexualidade, ao invés do termo transexualismo, comum em diversos textos e, também no linguajar cotidiano. Deste modo, é factível reconhecer no eixo das palavras "transexualismo" o sufixo "-ismo" (do grego ismós), que dá a ideia de "condição patológica" (BUENO, 1996), palavras que indicam um estado de doença. Nesta perspectiva, podemos citar o entendimento exposto por Ramsey (1998):

\footnotetext{
O transexualismo é definido como um descompasso entre o sexo psíquico e o sexo fenotípico ou biológico. Trata-se de uma disforia de gênero, ou seja, "refere-se àquele estado psicológico por meio do qual uma pessoa demonstra insatisfação com o seu sexo congênito e com o papel sexual, tal como é socialmente definido, consignado para este sexo, e que requer um processo de redesignação sexual cirúrgico e hormonal”. (RAMSEY, 1998, p.176)
}

As exposições biomédicas sobre transexualidade detêm o poder de estabelecer, com que indivíduos "trans" possam ser descritos aos métodos patológicos, tanto físico, no sentido dos sujeitos se submeterem à cirurgia de transgenitalização, como mentalmente, quando refere-se ao diagnostico dos indivíduos com prognóstico de um transtorno de identidade de 
gênero (García, 2009). Desta maneira, os métodos fazem com que os sujeitos se subordinem ao aparato médico regulador, uma vez que, nos dias de hoje, na maioria dos países, continua sendo necessário passar pela cirurgia de redesignação sexual para a obtenção do reconhecimento legal e social de sua identidade de gênero. Nesse sentido, relata Berenice Bento (2006):

Duas grandes vertentes de produção de conhecimento se encontram na temática da transexualidade: o desenvolvimento de teorias sobre o funcionamento endocrinológico do corpo e as teorias que destacaram o papel da educação na formação da identidade de gênero. (BENTO, 2006, p.42)

Sobrepõem à figura do "transexual verdadeiro", produzida e universalizada pelo saber médico, esbarrando-se em uma pluralidade de respostas para os conflitos entre corpo, sexualidade e identidade de gênero internas as práticas transexuais (BENTO, 2006). Contudo, as definições da transexualidade como "transtorno" ou "doença" se baseiam em certa concepção de gênero, transfigurada em etiologias. No entanto, não se trata de doença, mas sim mera questão de orientação sexual (LOURO, 2014). Caso contrário, se estaria incorrendo em discriminação e preconceito, utilizando o termo de forma pejorativa ou por ignorância, o que contraria o artigo $5^{\circ}$ da Constituição Federal, que não permite a discriminação em razão do sexo, ou de qualquer forma de discriminação.

1Visa-se a dignidade humana do transexual, como uma forma necessária de tratamento adequado, inclusive, quando refere-se à cirurgia de transgenitalização, proporcionando o amplo efeito de sua personalidade e a efetivação do direito à identidade sexual e à saúde, física e psíquica, promovendo-lhe vida digna (art. $1^{\circ}, \mathrm{III}, \mathrm{CF} / 88$ ). Contudo, não devemos esquecer que, em qualquer circunstância, que à dignidade da pessoa humana, o direito à identidade sexual, e, ainda, à plena liberdade de orientação sexual não deveram ser colocados empecilhos, construídos sob a base do preconceito e da ignorância, gerando discriminação e exclusão social.

Para Tereza Rodrigues Vieira, o direito deve andar de mãos dadas com o bom senso, assegurando a veracidade dos fatos, a liberdade de cada um sobre seu próprio corpo e deve curvar-se diante das legítimas necessidades da vida social e da ciência, sobretudo nos casos onde se objetiva o restabelecimento da saúde. Entretanto, não devemos esquecer que a experiência "trans" é povoada por corpos que escapam (BUTLER, 2013), que não conseguem encontrar sentido existencial nas cartografias disponibilizadas e aceitas socialmente. Baseando-se em compreensões concebidas a partir da instauração do dispositivo da sexualidade (FOUCAULT, 1997), propõem-se à desconstrução de corpos a partir da lógica binária de gênero. Desta forma, "não se deve descrever a sexualidade como um 
ímpeto rebelde, estranha por natureza e indócil por necessidade, a um poder que, por sua vez, esgota-se na tentativa de sujeitá-la e muitas vezes fracassam em dominá-la inteiramente" (FOUCAULT, 1997, p.98).

Contudo, a sexualidade não poderá ser reprimida, pois se visa objetivamente a sua pluralidade de sujeitos, em sentido amplo. Acompanhando certamente a constatação de que se vive, há algum tempo, uma proliferação e uma dispersão de discursos, bem como uma dispersão de sexualidades. (FOUCAULT, 1997). No entanto, a sexualidade e o poder são coextensivos, refutando implicitamente a postulação de uma sexualidade subversiva ou emancipatória que possa ser livre da lei (BENTO, 2006).

Certamente, o campo de poder em parte estruturado pelo gesto imperializante de apropriação dialética excede e abrange o eixo da diferença sexual, oferecendo um mapa de interseções diferenciais que não podem ser sumariamente hierarquizadas (BUTLER, 2013). A partir da desconstrução do dito "transexual verdadeiro" e da despatologização da experiência transexual (BENTO, 2006), considera-se que, os transexuais objetivam-se como sujeitos de direitos. Ressalta-se então a necessidade de retirar o termo "transexualismo" da lista de doenças.

Em que pese, sobrevém no dia 29 de janeiro, o dia da visibilidade de travestis e transexuais, com o objetivo de ressaltar a importância da diversidade e o respeito aos movimentos trans, representado por travestis, transexuais e transgêneros, marca-se a realidade de uma luta pelos direitos humanos e o respeito às identidades de gênero. A data foi criada pelo Ministério da Saúde em 2004, junto ao movimento brasileiro de travestis, transexuais e transgêneros, o que precisa ficar claro é que, não se trata apenas de um único dia, a luta tem que ser diariamente.

Com o intuito de colaborar com a luta por direitos humanos aos transexuais e travestis, o Conselho de Psicologia deu início, em 2014, um projeto direcionado ao esclarecimento e engajamento da categoria dos psicólogos na atuação pelos direitos humanos desta população e, principalmente, pela despatologização das identidades trans no atendimento à saúde. O objetivo do projeto é dar visibilidade a experiências culturais, políticas e subjetivas de gênero e sexualidade. O psicólogo Marco Aurélio Prado, membro da comissão de direitos humanos do Conselho Federal de Psicologia, destaca que: 
diagnóstico patologizador. Segundo ele, trata-se de uma prática classificatória e discriminatória (CONSELHO FEDERAL DE PSICOLOGIA, 2015).

Para isso, já foi realizado um debate sobre a temática com especialistas e com pessoas trans, envolvendo inclusive o Conselho Federal de Medicina, as conquistas estão sendo lentas, pessoas trans, infelizmente, ainda enfrentam muito preconceito da sociedade, portanto, não podemos silenciá-los. Desta forma, toda construção política, tais como a sexualidade e o gênero, que cerceiam nosso corpo e nossa subjetividade, tornam-se limitadoras e prejudiciais acerca de nossa constituição como seres humanos e indivíduos. Logo, toda construção política, deve ser refletida, problematizada e desconstruída.

\subsection{CIRURGIA DE TRANSGENITALIZAÇÃO}

A maioria da comunidade científica trata o "transexualismo" como doença, o qual possui, inclusive, um CID (Código Internacional de Doenças) - CID 10 F.64.0. Nesse sentido, trata-se de déficit de saúde, considerada como integridade psicofísica, que engloba uma tutela mais ampla do ser humano, com vistas a propiciar meios para que as pessoas possam se desenvolver de acordo com o sexo que julga, psicologicamente, pertencer (LOURO,2014).

Dessa forma, neste aspecto, é possível o tratamento do "transexualismo", em prol da realização do direito à saúde. Essa tem sido a forma mais factível para viabilizar, jurisprudencialmente, a cirurgia de transgenitalização, pois, sendo uma doença, deve receber tratamento correlato, inclusive custeado pelo Estado. Com base nesse argumento, foi editada Resolução $\mathrm{n}^{\circ} 1.652 / 02$, que autoriza hospitais públicos e privados, procedam à cirurgia de transgenitalização do tipo neocolpovulvoplastia (fenótipo masculino para feminino) e/ou procedimentos complementares sobre gônadas e caracteres sexuais secundários.

No entanto, a mesma resolução permite a realização de cirurgia do tipo neofaloplastia (fenótipo feminino para o masculino), com a diferença de que o procedimento acontecia somente a título experimental. Contudo, através da Portaria 2.803/13, ocorreram mudanças nesse sentido, estabelecendo que os transexuais masculinos tenham as cirurgias de retirada das mamas, do útero e dos ovários cobertas pelo sistema público. Passando também a ter direito à terapia hormonal para adequação à aparência masculina.

Tanto com relação aos homens, quanto com relação às mulheres, a definição de transexualismo obedecerá, no mínimo, aos seguintes critérios: desconforto com o sexo anatômico natural; desejo expresso de eliminar os genitais, perder as características primárias 
e secundárias do próprio sexo e ganhar as do sexo oposto; permanência desses distúrbios de forma contínua e consistente por, no mínimo, dois anos, e ausência de outros transtornos mentais (ART. $3^{\circ}$ RES. No 1652/02).

No tocante ao último critério, Tereza Rodrigues Vieira (2011) destaca o entendimento de

Alexandre Saadeh, psiquiatra do Hospital das Clínicas de São Paulo:

[...] a exclusão de patologias que possam se confundir com transtorno de identidade de gênero é de essencial importância, sobretudo quando se tem conhecimento de que não há critérios precisos de diagnóstico para o quadro e, portanto, o risco de má indicação cirúrgica ou mesmo errônea é significativa (VIEIRA, 2011, p. 413)

A autora salienta, porém, que este parecer não é unânime, de modo que há quem reclame a dispensa do diagnóstico psiquiátrico, afirmando que a transexualidade não necessariamente fixa um posicionamento subjetivo, e é preciso desvincular a condição sexual da postura patológica. Contudo, deve-se compreender a transexualidade como passível de várias formas de subjetivação. Além disso, a Resolução no 1.652/02, afirma que a cirurgia pode ser realizada se vinculada ao preenchimento de uma série de critérios: que o transexual se submeta a uma equipe multidisciplinar, formada, entre outros, por médicos, psicólogos e assistentes sociais, pelo período mínimo de dois anos, para que seja plenamente certo do seu propósito de se submeter à cirurgia.

Em continuidade, a Resolução $\mathrm{n}^{\mathrm{o}} 1.955 / 10$ do Conselho Federal de Medicina, estabeleceu a necessidade de cumprimento dos critérios estabelecidos no seu artigo $4^{\circ}$, quais sejam: 1) Diagnóstico médico de transgenitalismo; 2) Maior de 21 anos de idade; 3) Ausência de características físicas inapropriadas para a cirurgia. Assim, no Brasil, somente com o cumprimento das exigências da referida resolução é possível à realização da cirurgia de transgenitalização e tratamento para adequação de sexo do transexual, devendo o estabelecimento médico estar devidamente equipado e com profissionais habilitados a este tratamento. Além disso, os hospitais deverão ter comissão de ética, nos termos da legislação em vigor $\left(\operatorname{art.~} 5^{\circ}, \S^{\circ}\right)$.

Todavia, a natureza do "transexualismo" não se trata de uma doença, pois transexuais visam à busca por sua identidade pessoal, de maneira desatrelada do conceito de saúde. Visase situar a

problemática da cirurgia de transgenitalização, pois não são todas as pessoas que necessitam da mesma modificação corporal para a harmonização do sexo psíquico e morfológico. Há pessoas que se sentem perfeitamente adequadas apenas com o tratamento hormonal, há 
aquelas que necessitam da intervenção cirúrgica e, ainda, há aquelas que, mesmo prescindindo da intervenção cirúrgica, optam por permanecer com parte de seus órgãos sexuais ou reprodutivos. Os padrões médico cirúrgico devem adequar-se as necessidades individuais de cada transexual, pois as demandas são diversas e específicas.

\title{
3.2 BUROCRATIZAÇÃO DO SISTEMA ÚNICO DE SAÚDE
}

Podemos relatar, que o desejo de candidatos transexuais à cirurgia de transgenitalização pelo Sistema Único de Saúde - SUS tornava-se corroído em decorrência da negativa do Ministério da Saúde em custear tal procedimento. No entanto, não existia alegação para a não intervenção do custeio às cirurgias. Em que pese sua significância, em 2007 foi proferia uma decisão de primeiro grau, pelo Juiz Federal Roger Raupp Rios, impulsionando o Ministério da Saúde a manifestar-se sobre os procedimentos para a realização da cirurgia pelo SUS, segue parte da ementa do acórdão:

\begin{abstract}
A exclusão da lista de procedimentos médicos custeados pelo Sistema Único de Saúde das cirurgias de transgenitalização e dos procedimentos complementares, em desfavor de transexuais, configura discriminação proibida constitucionalmente, além de ofender os direitos fundamentais de liberdade, livre desenvolvimento da personalidade, privacidade, proteção à dignidade humana e saúde; O direito à saúde é direito fundamental, dotado de eficácia e aplicabilidade imediatas, apto a produzir direitos e deveres nas relações dos poderes públicos entre si e diante dos cidadãos, superada a noção de norma meramente programática, sob pena de esvaziamento do caráter normativo da Constituição (TRF, 2007).
\end{abstract}

Após a decisão, em 2008, proferida na Portaria ${ }^{\circ} 457$ do Ministério da Saúde, regulamentando os procedimentos de realização das cirurgias pelo Sistema Único de Saúde, porém para realização destas cirurgias os hospitais deverão estar habilitados e credenciados. Segundo o Ministério da Saúde, apenas cinco instituições no país estão habilitadas e credenciadas, a efetuarem cirurgia de transgenitalização. São elas: Hospital das Clínicas da Universidade Federal de Goiás; Hospital de Clínicas de Porto Alegre, da Universidade Federal do Rio Grande do Sul; Hospital Universitário Pedro Ernesto, da Universidade Estadual do Rio de Janeiro; Fundação Faculdade de Medicina, da Universidade de São Paulo; e Hospital das Clínicas da Universidade Federal de Pernambuco. No entanto, a estatística de 2008 até 2014, foi a realização de 6.724 procedimentos ambulatoriais e 243 procedimentos cirúrgicos via SUS.

Ainda que, os transexuais preencham os requisitos da portaria, bem como o da Resolução $n^{\circ} 1.955 / 10$, o processo é árduo. Deste modo, não basta o mero preenchimento dos 
requisitos e consequentemente os dois anos de acompanhamento por uma equipe multidisciplinar, com intuito

da obtenção do laudo médico que comprove a transexualidade, o indivíduo ainda deverá aguardar à cirurgia, em uma lista de espera, sem previsão de obtê-la. Nota-se, que a burocratização para o transexual ter assegurado o seu direito, de fazer a cirurgia de transgenitalização, e ser tratado conforme o gênero escolhido por ele é intrincada.

\section{RETIFICAÇÃO DO REGISTRO CIVIL: INTERESSES INDIVIDUAIS VERSUS INTERESSES SOCIAIS.}

A transexualidade emerge como forma de aplicação à intimidade do sujeito, bem como à livre realização da personalidade. Contudo incluem-se de outro modo limitações, inibições, modelos e mitos, em um evidente método de normalização, pois como relata Louro: a aparência é algo que se apresenta ou que se representa. Nesse sentido:

\footnotetext{
A determinação das posições dos sujeitos no interior de uma cultura remete-se, usualmente,

à aparência de seus corpos. Ao longo dos séculos, os sujeitos vêm sendo examinados, classificados, ordenados, nomeados e definidos por seus corpos, ou melhor, pelas marcas que são atribuídas a seus corpos (LOURO, 2003, p.01). grifo da autora.
}

Basicamente os corpos são intitulados ou discriminados conforme se ajustam, ou não, aos ditames e às normas culturais (BENTO, 2006). Neste compasso, a adequação do nome registral bem como de gênero estão perante os holofotes do direito, podendo tornar-se intérprete de repressões e infelicidades quando não se amoldam à realidade da pessoa a quem deveriam representar. Assim:

\footnotetext{
Diante desse quadro de maior liberdade individual, passa a ser cada vez mais comum pessoas que, na sua livre expressão de sua personalidade, deixam de identificar-se com o nome registral, o que pode inaugurar uma problemática de ordem pessoal e também social. Na primeira hipótese, a pessoa pode sentir-se constrangida com o nome, uma vez que não mais corresponde a seu caractere identificador, fazendo, portanto, com que este deixe de cumprir sua principal função [...] (SANCHES, 2011, p. 426).
}

Perante a construção do direito à identidade de aspecto individual (BRAUNER, 2006), o registro civil atribui reflexão de uma nova realidade, através da adequação do nome e do sexo, em razão de ser meio de prova do estado da pessoa, pois é justamente através da atribuição nominativa que passamos a ter representatividade individual no meio social em que vivemos, evidenciando assim o direito da personalidade descrito no art. 16 do Código 
Civil. Desta forma, o gênero sexual que deve constar no registro civil é aquele apto a concretizar a identidade sexual real da pessoa e não sua identidade formal (VIEIRA, 2008).

Entretanto, dentre as características atribuídas ao nome civil, à doutrina compreende razões que alegam o fato de o nome estar ligado a preceitos de ordem pública, tornando a certidão de nascimento prova da existência dos sujeitos e sua admissão no mundo jurídico. Permeando este fundamento como forma de negar a troca de nome ao transexual e fazendo com que muitos optem

pela cirurgia de transgenitalização, como um meio plausível de obtenção da troca de documentos.

Compreende a doutrina:

\begin{abstract}
Que o principal problema é, portanto, a adoção pelo direito do princípio da imutabilidade relativa dos assentos de nascimento, no lugar da mutabilidade, significando isto que o nome não pode ser mudado depois de assentado no registro civil, a não ser em casos de erro gráfico ocorrido por ocasião do registro. Este princípio utiliza o modelo biomédico para sua formação, sendo a morfologia genital o que lhe dá sustentação. A mudança de prenome pelo transexual não teria, assim, guarida no direito brasileiro (ZAMBRANO, 2003, p. 85).
\end{abstract}

Como forma de desconstrução do modelo biomédico, a característica de imutabilidade é absolutamente contestável, vez que a própria legislação prevê hipóteses de sua alteração, aplicando-se o princípio da dignidade da pessoa humana (art. $1^{\circ}$, III, da CF/1988), bem como o da solidariedade social (art. 3º, I, da CF/1988). No entanto, é imprescindível à segurança das relações que tais alterações registrais no prenome sejam realizadas através de processos judiciais, de minucioso procedimento para averiguação dos reais motivos, ressaltando-se o interesse de terceiros (SANCHES, 2011).

Nessa seara o registro deve adequar-se ao transexual, demostrando sua titulação de direitos atinentes ao sexo e ao nome civil, para que ele tenha acesso aos moldes inerentes a seu novo estado individual, pois a possibilidade de mudança de nome é um processo fundamental na construção e redefinição do gênero. Visto que a certificação do reconhecimento, do tratamento cirúrgico e das modificações corporais não tem sentido se estas não forem contempladas pela mudança do registro civil. De tal forma:

O direito à identidade pessoal compreende primeiramente o direito ao nome (prenome e sobrenome), mas também íntima ligação com o direito à própria imagem e à intimidade. Há que se considerar que dentre as características fundamentais das sociedades contemporâneas está na importância do cidadão, de sua auto identidade e da expressão da diversidade sexual (BRAUNER, 2006). 
Assim, o nome deve refletir o âmago da personalidade individual, condizer com seu estado pessoal e social, bem como deve estar consorte com o seu psiquismo, sua honra, imagem pessoal e social, não podendo ser ridículo ou vexatório (VIEIRA, 2008). No entanto, a realidade de um transexual se faz distinta, pois a conjuntura de ainda não existirem normas sobre a destinação jurídica da cirurgia de transgenitalização, faz com que grande parcela dos transexuais recorra ao Poder Judiciário pedindo o devido reconhecimento de seus direitos para alteração de nome, prenome e sexo no registro civil.

Todavia, com ações jurídicas e políticas cada vez mais intentadas, perfazem uma fixação de entendimentos jurisprudenciais, de que o estado civil de sujeitos não é uma partícula indisponível, possibilitando desde a mudança de nome, a troca de estado civil e, passando pela intervenção cirúrgica, o direito admite a identidade sexual como unidade preeminente do livre desenvolvimento

da personalidade, e de alguma maneira compreender a autonomia sexual, ensejando pensar no acolhimento de novos paradigmas. Isto é, defronte a desconstrução dos órgãos genitais genéticos e originários, seria fundamental ter seu nome e sexo correspondentes a esta outra identidade.

Faz-se relevante mencionar que já existem jurisprudências para a troca de nome de transexuais no Brasil, porém permanece uma discussão a respeito da possibilidade de mudança do gênero na certidão de nascimento. Desta forma, podemos relatar que:

\begin{abstract}
As decisões são pacificadas no sentido de permitir a cirurgia com alteração do nome, mas são vacilantes quanto à alteração do gênero sexual na certidão de nascimento, tendo em vista que estariam a permitir uma informação equivocada, pois, de fato, o indivíduo não nasceu com aquela característica [...] A segurança jurídica das relações sócias e a necessidade da verdade real são questões importantes e aparentemente apresentam um entrave à proposta (SANCHES, 2011, p. 429).
\end{abstract}

Diante de pedidos de alteração de gênero cada vez mais ocorrentes, o Poder Judiciário tem estado na vanguarda, pois ainda a sociedade brasileira vê-se carente de uma legislação específica que regule tal hipótese. Contudo, não obstante a democratização da cirurgia represente um grande avanço, ainda resta pendente a normatização da alteração do prenome e do sexo no registro de nascimento e demais documentos de identificação dos transexuais (BRAUNER E GRAFF, 2012).

\title{
4.1 PROJETOS DE LEI
}


O Projeto de Lei $\mathrm{n}^{\mathrm{o}}$ 70/95, de autoria do ex-Deputado José de Castro Coimbra, encontra-se em tramitação na Casa Legislativa há quase duas décadas, aguardando votação. O Projeto propõe o acréscimo de um parágrafo ao artigo que define o delito de lesões corporais, estabelecendo como excludente do crime a intervenção cirúrgica destinada à alteração do sexo. Também busca a mudança da Lei dos Registros Públicos para possibilitar, mediante autorização judicial, a retificação do prenome. Prevê a averbação no registro de nascimento e no respectivo documento de identidade que se trata de um transexual.

Contudo, o aludido Projeto de Lei, apesar de atitude elogiável à época em que foi anunciado, perdeu o seu objeto defronte aos atuais preceitos que regem o processo transexualizador e as operações cirúrgicas que lhes são pertinentes. A Portaria $n^{\circ} 2.803$, de 19 de novembro de 2013, do Ministério da Saúde, é a diretriz infra legal que define e amplia o processo transexualizador no âmbito do Sistema Único de Saúde. Ela dispõe sobre todas as diretrizes de assistência ao usuário desse tipo de intervenção, o que constata claramente que a matéria objeto do Projeto de Lei ${ }^{\circ} 70 / 95$, encontra-se superada, não sendo mais considerado criminoso o médico cirurgião que realiza cirurgias transexualizadoras.

Já o Projeto de Lei 6655/06, apresentado pelo deputado Luciano Zica, encontra-se no Senado Federal aguardando apreciação, em sua ementa propõem a permissão da substituição do

prenome da pessoa transexual. A proposta modifica a Lei 6015/73, relativa aos registros públicos, e pleiteia apenas o reconhecimento do transexual por laudo médico, independentemente de ele ter sido ou não submetido a uma cirurgia para adequação dos órgãos sexuais. Além disso, a proposta determina que a sentença relativa à troca do nome será objeto de averbação no livro de nascimento, na qual será obrigatória a menção ao fato de se tratar de uma pessoa transexual.

A comissão de constituição e justiça e de cidadania em sua redação final, aprova a alteração do art. 58 da Lei $n^{\circ}$ 6.015, de 31 de dezembro de 1973, que dispõe sobre registros públicos e dá outras providências, possibilitando a substituição do prenome de pessoas transexuais. Nesse sentido:

Decretando o Congresso Nacional: Art. $1^{\circ}$ Esta Lei altera o art. 58 da Lei $n^{\circ}$ 6.015, de 31 de dezembro de 1973, que dispõe sobre os registros públicos e dá outras providências, possibilitando a substituição do prenome de pessoas transexuais. Art. $2^{\circ} \mathrm{O}$ art. 58 da Lei $\mathrm{n}^{\circ} 6.015$, de 31 de dezembro de 1973, passa a vigorar com a seguinte redação: "Art. 58. O prenome será definitivo, admitindo-se, todavia, a sua substituição, mediante sentença judicial, nos casos em que: I - o interessado for: a) conhecido por apelidos notórios; b) reconhecido como transexual de acordo com laudo de avaliação médica, ainda que não tenha sido submetido a procedimento 


\begin{abstract}
médico cirúrgico destinado à adequação dos órgãos sexuais; II - houver fundada coação ou ameaça decorrente da colaboração com a apuração de crime por determinação, em sentença, de juiz competente após ouvido o Ministério Público. Parágrafo único. A sentença relativa à substituição do prenome na hipótese prevista na alínea b do inciso I do caput deste artigo será objeto de averbação no livro de nascimento com a menção imperativa de ser a pessoa transexual." (PICCIANI E RÊGO FILHO, 2007)
\end{abstract}

No entanto, encontra-se em tramitação na Câmara dos Deputados o Projeto de Lei 5.002/2013, de cunho muito importante e relevante pois trata da viabilização e desburocratização para o sujeito ter assegurado, por lei, o direito de ser tratado conforme o gênero escolhido por ele, ou seja, dispõe sobre o direito à identidade de gênero alterando o art. 58 da Lei $n^{\circ} 6.015$ de 31 de dezembro de 1973. O projeto é denominado de lei João W. Nery, lei de Identidade de Gênero de autoria do deputado Jean Wyllys e da deputada Erika Kokay.

Todavia, a proposta tende proporcionar que cada sujeito seja compreendido em seu íntimo, no sentido de ser tratado como quiser, sendo homem ou mulher, ou seja, qualquer sujeito que desejar poderá demandar a retificação do registro civil, desde que demonstrem alguns requisitos. Entretanto funcionários dos cartórios poderão demandar a retificação do registro civil, sem necessitar de trâmites judiciais ou autorizações judiciais, para formular novos documentos, como certidões de nascimento, documentos de identidade e outros que exigem mudanças.

Portanto, após a manifestação de autorização da cirurgia de transgenitalização no Brasil ser reconhecida, ainda carecemos de uma lei específica para que os sujeitos transexuais possam alterar o seu sexo e nome no registro civil, no sentido de não serem mais prejudicados e constrangidos em seus cotidianos. Pois, como relatado, não existem leis que legitimem e protejam transexuais da intolerância alheia.

\title{
4.2 POLÍTICAS PÚBLICAS VOLTADAS AO PRINCÍPIO DA DIGNIDADE DA PESSOA HUMANA AOS TRANSEXUAIS
}

Podemos entender políticas públicas como diretrizes voltadas às ações do poder público, para mediar relações entre sociedade e Estado. No entanto, o seu método de elaboração e implantação, distributivo ou redistributivo, são moldes de exercício do poder político, envolvendo diversos interesses sociais. Deste modo, há uma necessidade de mediar 
estas relações, com o objetivo de obter um consenso e uma real eficácia nas políticas públicas, sejam elas sociais ou institucionais.

A política em si caracteriza-se como o diálogo entre sua formulação e sua implementação, ou seja, a interação entre o que se propõe executar e o que realmente se executa (SAMPAIO; ARAÚJO JR, 2006). Neste sentido, implementar políticas públicas constitui em determinar o que deverá ser estabelecido, qual a sua importância e quem será atingido com eventuais resultados. São definições concernentes com a estrutura de organização da sociedade e, com a cultura política contemporânea.

Pode-se deduzir, inclusive, que a política surge como resposta ao contexto, interferindo e sendo reformulada pelo mesmo. Isso implica em dizer que as políticas públicas são históricas e comprometidas com determinados contextos, seja com o objetivo de modificá-los, ou perpetuá-los (SAMPAIO; ARAÚJO JR, 2006). No entanto, nem sempre há compatibilidade entre as intervenções e declarações de vontade e as ações desenvolvidas.

Por isso, nesta lógica, o Estado deverá promover os direitos humanos, com base no princípio da dignidade da pessoa humana, garantindo uma real elaboração e implementação de diretrizes voltadas aos transexuais.

Entretanto, torna-se incumbência do Estado e Sarlet a defini como:

A qualidade intrínseca e distintiva de cada ser humano que o faz merecedor do mesmo respeito e consideração por parte do Estado e da comunidade, implicando, neste sentido, um complexo de direitos e deveres fundamentais que assegurem a pessoa tanto contra todo e qualquer ato de cunho degradante e desumano, como venham a lhe garantir as condições existenciais mínimas para uma vida saudável, além de propiciar e promover sua participação ativa e co-responsável nos destinos da própria existência e da vida em comunhão com os demais seres humanos. (SARLET, 2002, p.60)

Visa-se neste âmbito, um conjunto de políticas públicas que procure compreender dinâmicas, concepções e implementações à sujeitos transexuais. Contudo, apesar de uma interlocução entre Estado e sociedade, o vasto desafio é transformar as políticas públicas em efetivas. O princípio da dignidade da pessoa humana pode e deve ocasionar soluções em cada caso

concreto, no sentido de obter uma concordância entre eles, pois na medida em que acolhermos o princípio, não deverá desprezar os seus demais valores. Nesse sentido, a doutrina relata:

O expresso reconhecimento da dignidade da pessoa humana como princípio fundamental traduz, em parte, a pretensão constitucional de transformá-lo em um 


\begin{abstract}
parâmetro objetivo de harmonização dos diversos dispositivos constitucionais, obrigando o intérprete a buscar uma concordância prática entre eles, na qual o valor acolhido no princípio, sem desprezar os demais valores constitucionais, seja efetivamente preservado. Enquanto valor incerto em princípio fundamental a dignidade da pessoa humana serve de parâmetro para a aplicação, interpretação e integração de todo o ordenamento jurídico, o que ressalta o seu caráter instrumental. Quando a Constituição elencou um longo catálogo de direitos fundamentais e definiu os objetivos fundamentais do Estado, buscou essencialmente concretizar a dignidade da pessoa humana. (MARTINS, 2003, p.124)
\end{abstract}

Desta forma, o poder público possui um papel relevante, o de propiciar a multiplicidade na produção (construção) de diferenças corporais e sexuais. Tornando-se necessário, especialmente para os direitos humanos, que a sexualidade seja discutida constantemente, expondo que não há uma única maneira possível de performatividade (BUTLER, 2013). Sendo imprescindível continuarmos lutando não só com as implementações de projeto de lei, mas também com os embates de forças sociais, visando implementações das políticas públicas que de fato asseverem a universalização do direito à dignidade da pessoa humana de qualidade a todos os sujeitos.

\title{
5. CONSIDERAÇÕES FINAIS
}

Diante de tudo que se expôs sobre a questão da transexualidade, devemos frisar a capacidade de abarcar novos sujeitos e experiências, tornando-se desta forma, importantes e necessários. Pois ainda não há lei específica que trate do assunto, apenas projetos de lei em trâmite sem qualquer posição definitiva. É necessário um avanço através de políticas públicas referente a questões de gênero e sexualidade. Não é o direito a saúde do sujeito "transexual verdadeiro" que pleiteamos, mas sim o reconhecimento da dignidade da pessoa humana, personalidade e de uma livre orientação exercício da sexualidade.

Percebe-se que a ideia de gênero deve ser entendida além dos parâmetros socioculturais que identificam o que é masculino e feminino e que ela se conecta com as identificações histórico-sociais dos indivíduos que se veem como masculinos e/ou femininos. A questão da identidade sexual se dá na forma como os sujeitos percebem e vivenciam a sua orientação sexual, seus anseios sexuais das mais diversificadas maneiras e de acordo com a construção cultural e única de cada um. Entende-se que a expressão gênero é a maneira pela qual o sujeito exterioriza em sociedade o gênero masculino e/ou gênero feminino assim integralmente afastado da ideia de sexo biológico. 
A partir disso, no quadro da transexualidade, à angústia gerada pelo sentimento de inadequação de seu corpo com a sua identidade de gênero, torna-se nítida a necessidade de possibilitar um tratamento médico adequado. Podemos dizer, portanto, que o sofrimento decorre da incoerência entre o sexo biológico e a identidade de gênero. O transexual deverá ver-se como sujeito pleno de direitos constitucionais, nesse sentido referindo-se como um dos caminhos que se mostram viáveis para a concretização da nova postura pretendida, que é a ampliação da chave interpretativa do sistema jurídico através de uma releitura sob a orientação dos princípios constitucionais, com destaque para o princípio da dignidade da pessoa humana.

A efetivação dos direitos dos transexuais é fundamental para a aplicação dos princípios que norteiam a readequação sexual, como o princípio da dignidade da pessoa humana, da igualdade, da autonomia de vontade, da liberdade, etc. Se a intenção do direito está no bem-estar do próprio sujeito, a negação da escolha sexual ao transexual, bem como o seu reconhecimento é transgredir gravemente os seus direitos da personalidade. Ademais a identidade de gênero e a sexualidade não devem ser ignoradas por parte do ordenamento jurídico, visto que são direitos personalíssimos e por isso, tutelados constitucionalmente.

Dessa forma, convém salientar que o presente trabalho buscou abordar questões relevantes do cotidiano de transexuais, tanto socialmente como juridicamente, não obstante a existência de diversas outras problemáticas relacionadas. Ademais uma maior compreensão das questões de identidade, gênero e transexualidade a partir de um olhar amplo, da relação dignidade humana/ cirurgia de redesignação sexual. Tudo isso, trazendo a baila preocupações atinentes aos aspectos legais, denotando que o Brasil deve adequar suas leis de maneira que permitam uma boa convivência e reforce os valores sociais, respeitando os direitos fundamentais e a humanidade dos transexuais. 


\section{REFERÊNCIAS BIBLIOGRÁFICAS}

ASSOCIATION. American Psychiatric. Disponível em: www.psychiatry.org. Acesso em abril de 2015.

BENJAMIN, Harry. The Transsexual Phenomenon. The Julian Press: Publishers. New York, 1966.

Disponível em:

http://www.symposion.com. Acesso em 29 de maio de 2015.

BENTO, Berenice. A reinvenção do corpo: sexualidade e gênero na experiência transexual. Rio de Janeiro: Garamond Universitária, 2006.

BUENO, Francisco da Silveira. Minidicionário da Língua Portuguesa. São Paulo: FTD S.A, 1996.

BUTLER, Judith. Problemas de gênero: feminismo e subversão da identidade. Tradução de Renato Aguiar. $5^{\circ}$ ed.

Rio de Janeiro: Civilização Brasileira, 2013.

BRASIL. Constituição da República Federativa do Brasil de 1988. Vade Mecum. São Paulo: Saraiva, 2015. Anais da Conferência Nacional de Gays, Lésbicas, Bissexuais, Travestis e Transexuais - GLBT. Disponível em http://www.sdh.gov.br. Acesso em abril de 2015.

Conselho Federal de Pscicologia. Disponível em: http://site.cfp.org.br. Acesso em abril de 2015.

DATASUS - Departamento de Informática do SUS. Disponível em: www.datasus.gov.br. Acesso em maio de 2015.

Portaria no 457 de 19 de agosto de 2008 do Ministério da Saúde. Disponível em: http://bvsms.saude.gov.br. Acesso em abril de 2015

Portaria $\mathrm{n}^{\circ} \mathbf{2 . 8 0 3}$ de 19 de novembro de 2013 do Ministério da Saúde. Disponívelem: http://bvsms.saude.gov.br. Acesso em abril de 2015.

Projeto de Lei 5002 de 2013 da Câmara do Congresso Nacional. Disponível em: http://www.camara.gov.br. Acesso em abril de 2015. 
Resolução do Conselho Federal de Medicina no 1.482 de 1997. Disponível em: www.portalmedico.org.br.

Acesso em abril de 2015.

\section{Resolução do Conselho Federal de Medicina $\mathbf{n}^{\mathbf{0}} \mathbf{1 . 6 5 2}$ de 2002.} Disponível em:

http://www.portalmedico.org.br. Acesso em maio de 2015.

\section{Resolução do Conselho Federal de Medicina $\mathbf{n}^{\circ} \mathbf{1 . 9 5 5}$ de 2010.} Disponível em:

http://www.portalmedico.org.br/. Acesso em abril de 2015.

World Health Organization ICD-10. Disponível em: http://apps.who.int/. Acesso em abril de 2015.

World Professional Association for Transgender Health. Disponível em: www.wpath.org/. Acesso em abril de 2015.

BRAUNER, Maria Claudia Crespo; GRAFF, Laíse. Aspectos bioéticos da cirurgia de redesignação sexual sob a ótica da realização do direito fundamental à saúde. In: Direitos Fundamentais \& Justiça, Ano 6, n. 18, Porto Alegre: HS Editora, jan./mar.n. 2012, p. 149-168.

à .; MOURA, Oyára Cristina Costa de. Transexualidade: a redefinição da sexualidade e o direito

identidade pessoal. In: Direito e Cidadania. In: LOBATO, Anderson Orestes Cavalcante; LONDERO, Josirene Cândido; DANTAS, Roberto Ribeiro Dantas (Org.). Juiz de Fora: Editar, 2006, p. 77.

COACCI, Thiago. Encontrando o transfeminismo brasileiro: um mapeamento preliminar de uma corrente em ascensão. História Agora, v. 1, 2013, p. 134-161.

FOUCAULT, Michel. História da Sexualidade I: A vontade de saber. Trad. Maria Thereza da Costa Albuquerque e $\mathrm{J}$.

A. Gilhon de Albuquerque. Rio de Janeiro: Edições Graal, 1997.

GARCÍA, Francisco Vásquez. Del sexo dicotómico al sexo cromático. La subjetividad transgenérica y los límites del constructivismo. Sexualidad, Salud y Sociedad - Revista Latinoamericana. n.1, p. 63-88, 2009. Disponível em http:// www.sexualidadsaludysociedad.org. Acesso em 12 abril de 2015.

JUSTIÇA FEDERAL. Tribunal Regional Federal da 4 ${ }^{a}$ Região. Apelação Cível n. 2001.71.00.026279-9. Terceira Turma. Relator: Roger Raupp Rios. Julgado em 22/08/2007. Disponível em: http://www2.trf4.jus.br/trf4/. Acesso em maio de 2015.

LOURO, Guacira Lopes. Gênero, sexualidade e educação: Uma perspectiva pós-estruturalista. Petrópolis, $\mathrm{RJ}$ :

Vozes, 2014. p.18-40.

2003.

. Corpos que escapam. Mesa-redonda nº 58. Eixo temático 7 - Educação, Infância e Juventude.

Disponível em: http://www.portalanpedsul.com.br. Acesso em 04 de maio de 2015.

MARTINS, Flademir Jerônimo Belinati. Dignidade da Pessoa Humana: Princípio Constitucional Fundamental.

Curitiba: Juruá, 2003.

PICCIANI, Leonardo; RÊGO FILHO, Vital do. Comissão de constituição e justiça e de cidadania. Disponível em:

http://www.camara.gov.br/. Acesso em junho de 2015.

RAMSEY, Gerald. Transexuais: perguntas e respostas. Trad. Rafael Azize. São Paulo: Summus, 1998. 
RIOS, Roger Raupp. O Princípio da Igualdade e a Discriminação por Orientação Sexual. A homossexualidade no Direito Brasileiro e Norte-Americano. São Paulo. 2002. Revista dos Tribunais. p $127-$ 147.

Em Defesa dos Direitos Sexuais. Porto Alegre: Livraria do Advogado, 2007.

RYAN. Hugh. A bathroom of one's own. Disponível em: http://hughryan.org. Acesso em abril de 2015.

SAMPAIO, Juliana; ARAÚJO JR, José Luis. Análise das políticas públicas: uma proposta metodológica para o estudo no campo da prevenção em aids. Rev. Bras. Saúde Materno. Infantil. Recife, v. 6, n. 3, p. 335 346 , jul/set 2006 .

SANCHES, Patrícia Corrêa. Mudança de nome e da identidade de gênero. In: Maria Berenice Dias. (Org.). Diversidade Sexual e Direito Homoafetivo. Diversidade Sexual e Direito Homoafetivo. São Paulo: Revista dos Tribunais, 2011, p. 425-444.

SARLET, Ingo Wolfgang. Dignidade da pessoa humana e direitos fundamentais. $2^{\circ}$ ed. rev. e amp. Porto Alegre:

Livraria do Advogado, 2002

SCHILT, Kristen. Transsexual . Encyclopedia of Gender and Society. 2008. SAGE Publications. Disponível em http://www.sageereference.com. Acesso em 24 de abril de 2015.

SCOTT, Joan. Gender and the politics of history. New York: Columbia University Press. 1988.

SGRECCIA, Elio. Manual de bioética I - Fundamentos e Ética Biomédica. Ed:Loyola. São Paulo. 2002. p. 500-509

SZANIAWSKI, Elimar. Limites e possibilidade do direito de redesignação do estado sexual. Estudo sobre o transexualismo: aspectos médicos e jurídicos. São Paulo: Revista dos Tribunais, 1999.

TEIXEIRA, Ana Carolina Brochado; RODRIGUES, Renata de Lima. O Direito das famílias entre a norma e a realidade. São Paulo: Atlas, 2010. p.67-86.

UNISINOS. Instituto Humanista. Transexualidade. "Nós fazemos gênero no dia a dia". Entrevista especial com Berenice Bento. Disponível em: http://www.ihu.unisinos.br. Acesso em abril de 2015.

URIBE. Gustavo; FALCÃO. Jaqueline. Brasil faz duas cirurgias de mudança de sexo a cada dia: O Globo. Disponível em: http://oglobo.globo.com. Acesso em abril de 2015.

VIEIRA, Tereza Rodrigues. Nome e Sexo: mudanças no registro civil. São Paulo: RT, 2008.

Homoafetivo.

Transexualidade. In: Maria Berenice Dias. (Org.). Diversidade Sexual e Direito

Diversidade Sexual e Direito Homoafetivo. São Paulo: Revista dos Tribunais, 2011, p. 412-424.

; SEGRE, Marco. Bioética e sexualidade. São Paulo: Jurídica Brasileira, 2004.

ZAMBRANO, Elizabeth. Trocando os documentos: Um estudo antropológico sobre a cirurgia de troca de sexo. Dissertação de Mestrado, Instituto de Filosofia e Ciências Humanas. Universidade Federal do Rio Grande do Sul. Porto Alegre, 2003. 